\title{
Pengembangan Kurikulum PAUD Berbasis Alam
}

\author{
Dzurrotul Kamelia \\ Email : melycamelia0@gmail.com \\ Nurillah \\ Email : nurielzoufan@gmail.com \\ Siti Uzlifatul Jannah \\ Email : Uzlifatuljannah277@gmail.com \\ Yustika Wira Pratiwi \\ Email : yustikawp080@gmail.com \\ Institut Agama Islam Negeri Madura
}

\begin{abstract}
Classroom learning (indoor) has become one of the most common learning models in society from ancient times to the present. Though learning can be done inside or outside the classroom. Even more so for young children who, if placed in the classroom alone, usually do not develop their abilities. A new innovation in education by implementing a nature-based curriculum in early childhood. This journal aims to describe the development of a nature-based curriculum in early childhood. Using qualitative research methods. Data collection tools used are books and ebooks and pdfs. In this research there is an understanding, the principles of natural-based curriculum development, as well as the steps in learning the nature-based curriculum consisting of planning, implementation and evaluation. In planning consists of determining the stage of development of students, setting indicators, compiling the concept of learning materials, determining themes, compiling plans for nature-based learning activities, preparing learning resources and teaching aids based on learning. In the implementation of learning done in the classroom and outside the classroom. Evaluation of learning is done by observing, anecdotal notes, and portfolios then poured in report cards containing details of the child's development so far
\end{abstract}

Keywords : Development, curriculum, natural

\begin{abstract}
Abstrak
Pembelajaran di dalam kelas (indoor) menjadi salah satu model pembelajaran yang sudah lumrah di kalangan masyarakat dari zaman dulu hingga sekarang. Padahal pembelajaran bisa dilakukan di dalam ataupun luar kelas. Terlebih lagi untuk anak usia dini yang bila ditempatkan di dalam kelas saja biasanya mereka kurang mengembangkan kemampuan mereka. Sebuah inovasi baru di bidang pendidikan dengan menerapkan kurikulum berbasis alam pada anak usia dini. Jurnal ini bertujuan untuk mendeskripsikan pengembangan kurikulum berbasis alam pada anak usia dini. Menggunakan metode penelitian kualitatif. Alat pengumpul data yang digunakan adalah dengan buku-buku dan ebook serta pdf. Dalam penelitian ini terdapat pengertian, prinsip-prinsip pengembangan kurikulum berbasis alam, serta langkah-langkah dalam pembelajaran kurikulum berbasis alam yang terdiri dari perencanaan, pelaksanaan dan evaluasi. Dalam perencanaan terdiri dari menetapkan tahap perkembangan anak didik, menetapkan indikator, menyusun konsep materi pembelajaran, menentukan tema, menyusun rencana kegiatan pembelajaran berbasis alam, menyiapkan sumber belajar dan alat peraga pembelajaran berbasis alam. Dalam pelaksanaan pembelajaran di lakukan didalam kelas dan diluar
\end{abstract}


kelas. Evaluasi pembelajaran dilakukan dengan pengamatan, catatan anekdot, dan portofolio kemudian dituangkan dalam raport yang berisi detail perkembangan anak selama ini.

Kata kunci : pengembangan, kurikulum, alam

\section{PENDAHULUAN}

Anak usia dini merupakan anak yang berusia 0 sampai 6 tahun. Masa ini disebut sebagai masa keemasana pada tahun ke 3 sampai 5 . Karena pada masa ini peluang perkembangan anak sangat berharga, semua potensi yang dimilikinya mengalami pertumbuhan dan perkembangan sangat pesat.

pendidikan anak usia dini yang banyak mengalami hambatan adalah masih terbatasnya penguasaan ilmu pendidikan para peserta didik, masih terbatasnya dana untuk pembelian alat permainan edukatif (APE), dan masih terbatasnya evaluasi program PAUD. Penyelenggaraan pendidikan di PAUD tersebut disebabkan oleh pendidik belum menguasai pendidikan untuk anak usia dini. Penguasaan pendidik PAUD terhadap anak sangatlah rendah. Banyak pendidik yang sudah terpola dengan pembelajaran yang sering ditemuka di sekolah dasar atau sekolah menengah pertama dan lainnya yaitu pembelajaran di indoor. Padahal, sesungguhnya proses belajar dapat dilakukan di mana saja termasuk di luar ruangan atau alam bebas. Proses belajar seperti tadi yang hanya outdoor akan menghambat proses mengeksplor kemampuan anak secara maksimal.

Untuk itu dalam Undang-Undang RI no 20 tahun 2003 tentang Sistem Pendidikan Nasional pasal 1 butir 14 dikemukakan bahwa pendidikan anak usia dini adalah " suatu upaya pembinaan yang ditujukan kepada anak sejak lahir (0 tahun) sampai dengan usia enam tahun yang dilakukan melalui pemberian rangsangan pendidikan untuk membantu pertumbuhan dan perkembangan jasmani serta rohani agar anak memiliki kesiapan dalam memasuki pendidikan lebih lanjut. Sejalan dengan amanat SISDIKNAS ini perlu ditunjang dengan kurikulum.

Kurikulum kerupakan salah satu komponen penting dalam proses pendidikan di Taman Kanak-Kanak. Oleh karena itu kurikulum untuk pendidikan 
anak usia dini perlu dikembangkan secara kreatif dan inovatif agar anak usia lebih mengembangkan perkembangannya secara maksimal.

Salah satu kurikulum yang kreatif dan inovatif adalah kurikulum berbasis alam. Lingkungan sekitar dapat dijadikan sebagai alternatif untuk kegiatan belajar mengajar. Model ini diharapkan dapat menjalin keselarasan antara materi pembelajaran dengan lingkungan alam sekitar. Alam memiliki banyak pengetahuan serta dapat digunakan sebagai tempat untuk melakukan proses belajar mengajar.

\section{PEMBAHASAN}

\section{A. Pengertian kurikulum PAUD Berbasis Alam}

Kurikulum merupakan seperangkat konsep yang mengatur tentang isi, tujuan dan proses pendidikan yang akan dilaksanakn. Konsep yang diatur dalam kurikulum bersifat tidak kaku.

Kurikulum PAUD berbeda dengan kurikulum pada jenjang pendidikan lainnya. pencapaian pada kurikulum PAUD adalah aspek perkembangan anak atau kematangan dalam perkembangan sesuai dengan tingkat usia anak, bukan kecakapan akademik dari suatu bidang studi. Adapun aspek perkembangan yang akan dicapai oleh setiap anak adalah : (1) nilai moral dan agama, (2) sosial emosional, (3) bahasa, (4) kognitif, (5) fisik motorik, (6) seni

Kurikulum PAUD berbasis alam adalah program pendidikan yang diberikan oleh suatu lembaga penyelenggara pendidikan yang media dan ruang belajaranya biasanya menggunakan alam, baik itu alam natural ataupun alam kelas buatan.

\section{B. Prinsip-Prinsip Pembelajaran PAUD Berbasis Alam}

Proses pembelajaran berbasis alam perlu memperhatikan sejumlah prinsip yang mendasarinya. Prinsip-prinsip yang dimaksud diantaranya adalah :

1. Berpusat pada perkembangan anak dan optimalisasi perkembangan 
Keberhasilan proses pembelajaran berbasis alam terletak pada peningkatan optimalisasi seluruh potensi perkembangan anak dengan menjadi lingkungan alam sebagai sumber belajar yang utama.

2. Membangun kemandirian anak

Proses pembelajaran yang berbasis alam diharapkan dapat membangun dan mengembangkan kemandirian, kedisiplinan dan sosialisasi agar terbentuk karakter kemandirian yang kuat. Dalam pembelajaran yang berbasis alam, anak akan terbiasa dihadapkan pada sejumlah persoalan kehidupan secara faktual.

3. Belajar dari lingkungan alam sekitar

Proses pembelajaran berbasis alam akan memaksimalkan pemanfaatan kekayaan alam yang ada, sebagai sumber ilmu pengetahuan.

4. Belajar dan bermain dari lingkungan sekitar

Melalui bermain, memungkinkan anak untuk terlibat dalam lingkunganny. Sehingga anak belajar melalui berbagai pengalaman dengan objek, orang, kegiatan yang ada disekitarnya. Pembelajaran yang dialami anak akan menjadi lebih menarik, menyenangkan (fun learning), bermakna dan tidak membosankan.

5. Memanfaatkan sumber belajar yang mudah dan murah

Dengan memanfaatkan lingkungan sekitar, anak dapat mempelajari banyak hal dari lingkungan terdekatnya (lingkungan alam, lingkungan fisik, lingkungan sosial, kultur budaya, dll) sehingga sumber belajar tidak harus sengaja dirancang dengan mengeluarkan biaya yang mahal

6. Pembelajaran menggunakan pendekatan tematik

Pembelajaran tema adalah salah satu pendekatan pembelajaran yang didasarkan atas ide-ide pokok/sentral tentang anak dan lingkungannya. Melalui pembelajaran tema dapat memberikan pengalaman langsung tentang objek yang riil bagi anak untuk menilai dan memanipulasinya, menumbuhkan cara berpikir yang komprehensif 
7. Membangun kebiasaan berpikir ilmiah sejak usia dini

Berpikir ilmiah yang dimaksud pada prinsip ini adalah memperkenalkan dan membiasakan anak untuk menemukan berbagai permasalahan yang ada di lingkungannya dan berpikir untuk menemukan cara memecahkannya. Kegiatan berpikir seperti ini dapat dilakukan mealui eksplorasi berbagai hal yang terjadi/ada dari lingkungannya, dari hal yang mudah/sederhana ke arah yang lebih kompleks/sukar

8. Pembelajaran inspiratif, menarik, kreatif dan inovatif

Anak adalah subjek dalam pembelajaran. Kegiatan-kegiatan pembelajaran perlu disiapkan untuk membangun rasa ingin tahu anak, memotivasi anak untuk berpikir kritis dan menemukan hal-hal yang baru

\section{Langkah-Langkah Pembelajaran Berbasis Alam}

Terdapat 3 langkah dalam pembelajaran berbasis alam, yaitu :

1. Perencanaan pembelajaran berbasis alam

Perencanaan pembelajaran terdiri dari menetapkan tahap perkembangan peserta didik, menetapkan indikator, menyusun konsep materi pembelajaran, menentukan tema, menyususn rencana kegiatan program semester (PROMES), kegiatan mingguan (RPM), dan harian (RPPH) berbasis alam, menyiapkan sumber belajar dan alat peraga pembelajaran berbasis alam.

Tahap awal dalam perencanaan pembelajaran berbasis alam dengan menetapkan tahap perkembangan anak didik. Masa anak usia PAUD merupakan masa yang paling penting sepanjang kehidupannya, masa usia dini merupakan masa peka bagi anak sehingga para ahli menyebutnya The Golden Age. Guru harus mampu mengetahui semua perkembangan anak didik dimana hal tersebut merupakan tahapan awal dari sebuah perencanaan pembelajaran. Pendidikan anak usia dini merupakan usia persiapan anak untuk menerima pendidikan selanjutnya di sekolah dasar. Sehingga dibutuhkan suatu 
pembelajaran yang mampu untuk merangsang perkembangan kompetensi anak usia dini.

Tahap kedua dalam perencanaan pembelajaran berbasis alam adalah dengan menetapkan indikator pembelajaran. Indikator pembelajaran dapat dijabarkan dengan membuat program semeste (PROSEM), rencana program pembelajaran mingguan (RPM), dan rencana program pembelajaran harian (RPPH). Biasanya perencanaan pembelajaran disusun sendiri oleh kepala sekolah dan guru, sehingga dalam penyusunannya dapat disesuaikan dengan visi, misi, dan tujuan sekolah serta kondisi yang ada di lapangan. Perencanaan pembelajaran dimulai dari penyusunan program semester. Pada program semester terdapat aspek perkembangan yang diharapkan dapat dicapai dalam waktu satu semester. Adapaun aspek-aspek perkembangan sesuai dengan standar tingkat pencapaian perkembangan dari Diknas. Indikator-indikator yang tercantum pada program semester diturunkan di rancangan pelaksanaan pembelajaran mingguan (RPPM). Setiap minggu ada indikator yang harus dicapai pada masing-masing aspek perkembangan. Pada RPPM harus terperinci indikator apa saja yang harus dicapai dalam waktu satu minggu. Dari RPPM diturunkan lagi pada rancangan pelaksanaan pembelajaran harian (RPPH). Pada RPPH terdapat tujuan yang harus dicapai anak melalui tema tertentu, maka indikator-indikator pembelajaran yang sudah ditentukan untuk hari tersebut harus dicapai. Tujuan guru menyusun RPPM dan RPPH yaitu untuk memudahkan guru dalam mempersiapkan bahan dan materi pembelajaran. Dalam menyusun RPPM dan RPPH guru dituntut untuk menguasai strategi pembelajaran dengan cara menguasai materi dengan baik sehingga dapat membuat persiapan pembelajaran.

Tahap ketiga yaitu guru menetapkan tema pembelajaran yang berbasis alam. Tema merupakan pokok pembelajaran yang akan disampaikan guru dalam proses pembelajaran. Setiap tema dibahas 
dalam satu minggu atau dua minggu tergantung dari keluasan cakupan dan kedalaman tema tersebut.

Tahap keempat yaitu menyusun konsep materi pelajaran berbasis alam. Tahap keempat ini merupakan sesuatu yang harus dilakukan guru, karena di dalam materi itulah akan disampaikan suatu pembelajaran yang bermakna dan amanat atau inti dari suatu pembelajaran. Materi dibuat berdasarkan tema yang sudah ditentukan. Ketika tema tanaman dan sub temanya sayuran maka guru harus bisa menentukan sayuran apa yang akan dibahas dalam sehari. Misal : menjelaskan sayur kangkung maka agar anak memahami apa itu kangkung, guru tidak sekedar menjelaskan tentang bagian-bagian kangkung, ciri-ciri, manfaat tetapi langsung mengajak anak didik ke kebun kangkung misalnya.

Tahap kelima yaitu penataan ruang kelas dengan memanfaatkan lingkungan alam. Perencanaan kelas yang memanfaatkan lingkungan alam dilakukan sesuai dengan tema yang akan disampaikan dalam pembelajaran.

Tahap keenam yaitu menyiapkan alat dan bahan peraga pembelajaran. Alat dan bahan pembelajaran berbasis alam dapat di luar kelas (outdoor) misalnya sains, berkebun, memancing, perosotan, jungkat jungkit, pasir, tumbuhan sekitar, kolam ikan, dan lainnya. sedangkan di dalam kelas misalnya perpustakaan, crayon, unit balok lego, bak air botol, puzzle, gunting, dan lainnya. hal tersebut dimaknai bahwa penataan ruang kelas yang baik dan terencana dengan berbagai macam media, alat dan bahan pembelajaran dapat meningkatkan pemahaman anak didik terhadap materi yang diajarkan oleh guru.

2. Pelaksanaan pembelajaran berbasis alam

Pembelajaran berbasis alam dimulai dari penyambutan, pelasanaan pijakan lingkungan, pijakan sebelum main, pijakan saat main, dan pijakan setelah main. Setiap hari anak akan disambut oleh beberapa guru, kemudian anak dibiasakan menaruh tas, melepas 
sepatu ditempat yang sudah disediakan. Setelah itu dimulailah pembelajarn oleh guru. Tujuan dari pelaksanaan pijakan lingkungan main untuk membantu dan memperlancar kegiatan main anak terkait alat main, menciptakan suasana lingkungan main yang menyenangkan bagi anak. Pelaksanaan pembelajarannya bisa di indoor ataupun outdoor. Pembelajran diluar kelas dibuat senyata mungkin dengan melihat, mengamati dan berinteraksi dengan objek secara langsung, sehingga pembelajaran tersebut menjadi bermakna dan dapat memberi pengalaman nyata. Sedangkan yang indoor dengan memindahkan alat yang berhubungan dengan alam seperti batu, pasir, tanah, daun, dan lainnya kedalam kelas. Kemudian anak didik dibuat kelompok dan disuruh mengamati.

3. Evaluasi pembelajaran berbasis alam

Penilaian yang dilakukan guru bisa dengan 3 cara yaitu penilaian dengan pengamatan, catatan anekdot, dan portofolio. Penilaian dengan pengamatan yaitu guru mengamati untuk menilai aspek afektif atau tingkah laku anak. Bisa dengan penilaian sendiri juga dengan penilaian rekan. Yang kedua penilaian dengan catatan anekdot dimana guru mencatat semua perkembangan anak didik selama pembelajaran berbasis alam. Catatan ini bisa berbentuk tabel yang isinya nomor dan jenis kegiatan. Juga untuk mengetahui sejauh mana perkembangan perilaku anak didik. Yang ketiga penilaian dengan portofolio yaitu dilakukan dengan cara mengumpulkan semua hasil karya anak didik dijadikan dalam satu file untuk bahan laporan dan untuk mengetahui perkembangan psikomotor anak didik.

\section{SIMPULAN}

Kurikulum PAUD berbasis alam merupakan program pendidikan yang diberikan oleh suatu lembaga penyelenggara pendidikan yang media dan ruang belajaranya biasanya menggunakan alam, baik itu alam natural ataupun alam kelas buatan. Terdapat prinsip-prinsip dalam pembelajaran PAUD berbasis alam yaitu : berpusat pada perkembangan anak, membangun kemandirian anak, 
belajar dari lingkungan alam sekitar, belajar dan bermain dari lingkungan sekitar, memanfaatkan sumber belajar yang mudah dan murah, pembelajaran menggunakan pendekatan tematik, membangun kebiasaan berpikir ilmiah sejak usia dini, serta pembelajaran inspiratif, menarik, kreatif, dan inovatif.

Langkah-langkah dalam pembelajaran berbasis alam terdiri dari perencanaan, pelaksanaan, dan evaluasi. Dalam perencanaan meliputi menetapkan perkembangan peserta didik, menetapkan indikator pembelajaran, menyusun konsep materi, menetapkan tema pembelajarn dan menyiapkan bahan alat peraga. Pelaksanaan pembelajaran dilaksanakan di luar dan dalam kelas. Evaluasi pembelajaran dilakukan dengan pengamatan, catatan anekdot, dan portofolio. Penilaian tersebut digunakan untuk mengukur kompetensi anak didik dan perkembangannya.

\section{DAFTAR PUSTAKA}

Astuti, Siti Utami. 2017. Implementasi Kurikulum Sekolah Alam Berbasis Pendidikan Islam Terpadu di Kelas V SDIT Alam Nuris. Jurnal Pendidikan Guru Sekolah Dasar Edisi 12 Tahun ke 6

Depdiknas. Kompetesi Guru (2007). Indonesia

Kurniawan, Heru. 2017. Sekolah Kreatif: Sekolah Kehidupan yang Menyenangkan untuk Anak. Yogyakarta: Ar-Ruzz Media.

Moslih, Ahmad dkk. 2018. Analisis Kebijakan PAUD : Mengungkap Isu-Isu Menarik Seputar PAUD. Jawa Tengah: Mangku Bumi

Septiani, Nifa. 2016. Penyelenggaraan Pembelajaran Berbasis Alam Guna Mengembangkan Karakter Kepemimpinan Anak Kelompok B di PAUD Alam Ungaran. Skripsi Sarjana. Fakultas Ilmu Pendidikan Universitas Negeri Malang.

Sunanik. 2018. Pembelajaran Berbasis Alam Untuk Anak Usia Dini di TK Alam A/Azhar Kutai Kartanegara. Jurnal Ilmiyah Al-Madrasah Vol 3 No.1 JuliDesember.

Wulansari, Betty Yulia. 2016. Pengembangan Model Pembelajaran Berbasis Alam Untuk Meningkatkan Kualitas Proses Belajar Anak Usia Dini. Jurnal Pendidikan dan Pemberdayaan Masyarakat

Yoewono, Haryono. 2015. Manajemen Kurikulum Pendidikan Anak Usia Dini Berbasis Alam di TK Sajmara Sukoharjo. Naskah Publikasi Tesis (tidak diterbitkan). Progrram Studi Manajemen Pendidikan Universitas Muhammadiyah Surakarta.

Yulianti, Sulistyawati. 2014. Kajian Kurikulum Sekolah Alam Dalam Rangka Mewujudkan Pendidikan Karakter Siswa Tingkat Sekolah Dasar. Jurnal Pendidikan dan Pengembangan SD Jilid I No 4 September. 
